\title{
Stepwise health surveillance for bronchial irritability syndrome in workers at risk of occupational respiratory disease
}

Wendel K Post, Katherine M Venables, David Ross, Paul Cullinan, Dick Heederik, Alex Burdorf

\begin{abstract}
Objectives-Questionnaires, lung function tests, and peak flow measurements are widely used in occupational health care to screen for subjects with respiratory disease. However, the diagnostic performance of these tests is often poor. Application of these tests in a stepwise manner would presumably result in a better characterisation of subjects with respiratory disease.

Methods-Cross sectional data from workers exposed to acid anhydrides, to laboratory animals, and to flour dusts were used. Sensitivity and specificity were calculated from cross tables of different (combinations of) tests for bronchial hyperresponsiveness and bronchial irritability in the past four weeks (BIS). From sensitivity and specificity likelihood ratios were computed and change in probability of BIS was calculated.
\end{abstract}

Results-The prevalence of BIS was $7 \%$, $7 \%$, and $5 \%$, respectively. In all groups questionnaire data provided excellent sensitivity but poor specificity, which was inherent on the broad definition of symptoms. Adding the forced expiratory volume in one second/forced vital capacity $\left(F_{1} V_{1}\right.$ /FVC) ratio yields almost perfect specificity, and peak expiratory flow (PEF) variability is intermediate in populations in which smoking induced or non-allergic respiratory diseases predominates. In occupational groups in which asthma is a problem, adding PEF measurements will optimise sensitivity and specificity in detection of BIS. The probability of BIS for subjects with a negative combined test outcome was lower than the probability before testing. Subjects with a positive combined test outcome had a probability of BIS after the tests at least three times the probability before.

Conclusions-Combined testing yields better sensitivity and specificity. An advantage of combined testing is an economy in the effort to screen for subjects with BIS. Combined testing resulted in more detailed estimation of the probability of BIS.

(Occup Environ Med 1998;55:119-125)

Keywords: bronchial irritability syndrome; asthma; COPD; occupational health surveillance; sensitivity; specificity; disease probability
In occupational health care, a questionnaire on respiratory symptoms - such as chronic cough, production of phlegm, wheezing, chest tightness or breathlessness, and spirometry, are the most widely used tests in surveillance programmes for obstructive lung diseases such as asthma and chronic obstructive pulmonary disease (COPD). For instance, in the United Kingdom, occupational physicians stated that the basis of the diagnosis in patients with occupational asthma reported to the surveillance of work related and occupational respiratory disease project (SWORD), included the history in $96 \%$ of the cases, lung function tests in $62 \%$, serial peak flow in $56 \%$, and serological measurement of IgE or IgG in $18 \%$. In $6 \%$ of the cases bronchial challenge was carried out. ${ }^{1}$ Because several tests are regularly used for detecting asthma a stepwise approach can be devised. $^{23}$ The stepwise combination of outcomes of tests may improve detection of subjects with disease. As there is no generally accepted definition of asthma or COPD, validation of a screening procedure comprising various tests should be evaluated by comparison with a selected standard.

Although measurement of non-specific bronchial hyperresponsiveness (NSBHR) has proved to be useful in the clinical assessment of patients with asthma or in occupational asthma, its usefulness in an epidemiological setting or occupational health care is still debatable. ${ }^{4}$ Presence of NSBHR is usually regarded as the defining physiological characteristic of asthma, ${ }^{56}$ but it is also associated with other respiratory diseases, such as COPD and bronchitis and with smoking. ${ }^{7}$ The NSBHR is affected by reduction in airway calibre, which can be caused by several factors such as smoking or respiratory disease. Studies of NSBHR among smokers with and without chronic bronchitis suggested that smoking, chronic bronchitis, and NSBHR are related. In particular, smokers with chronic bronchitis often have levels of NSBHR greater than nonsmokers, but less than asthmatic patients. It seems, therefore, of particular interest to the occupational physician to measure bronchial hyperresponsiveness to detect subjects with asthma or other respiratory disease - such as chronic bronchitis.

Disadvantages of using NSBHR as a gold standard is the demand on resources (apparatus, qualified personnel, and costs) and safety issues. Providing reasonable safety and stringent measures the test is not dangerous. A major disadvantage is that not all people with 
NSBHR report respiratory symptoms. ${ }^{89}$ In epidemiological studies the combination of symptoms and NSBHR has therefore been recommended. ${ }^{4} 1011$

In the current decision analysis study, we used the presence of NSBHR measured by histamine challenge testing in combination with questions on bronchial irritability in the past four weeks as the gold standard for the bronchial irritability syndrome (BIS). We have previously developed a nine item questionnaire of bronchial irritability symptoms for asthma epidemiology. ${ }^{12}$ Mortagy et al used bronchial irritability symptoms in conjunction with a fall of $20 \%$ or more in forced expiratory volume in one second $\left(\mathrm{FEV}_{1}\right)$ at a provocative concentration of $<0.5 \mathrm{~g} / 1$ histamine to describe BIS. They found that the bronchial irritability syndrome was closely associated with asthma, but that BIS and asthma cannot be considered synonymous, as most subjects with BIS had not been diagnosed as asthmatic. ${ }^{13}$

We chose the most widely used tests in occupational health care- that is, presence of respiratory symptoms, spirometry, and serial peak flow measurements as screening instruments. Within occupational health care, a questionnaire survey, followed by spirometry seems the most logical approach for sequential testing. The performance of combined testing to identify subjects with respiratory disease was examined in three occupational groups with exposures incriminated as causing respiratory disease, especially asthma: workers exposed to acid anhydrides, laboratory workers exposed to rats or mice, and workers with occupational exposure to flour dusts.

\section{Methods}

STUDY POPULATION

In the current study, data from studies among workers with exposure to acid anhydrides, laboratory animals, and flour dusts were analysed. These were the retrospective cohort study of 401 workers exposed to acid anhydrides; the baseline study of an ongoing follow up study among 323 laboratory animal workers who handled a variety of animals including rats, and another 61 laboratory animal workers who handled exclusively mice; and the baseline study of an ongoing follow up study 344 workers exposed to flour in bakeries and mills.

Survey methods are described in detail elsewhere. ${ }^{14} 15$
MEDICAL EXAMINATION

All participants were asked to complete a questionnaire on age, sex, smoking history, occupational history, and respiratory symptoms.

Calibrated leak free Vitalograph spirometers were used to record $\mathrm{FEV}_{1}$ and forced vital capacity (FVC). Up to six readings of FVC and $\mathrm{FEV}_{1}$ were recorded, with a minimum of three readings until two reproducible curves were achieved $\left(\mathrm{FEV}_{1}\right.$ and FVC within $\left.0.1 \mathrm{l}\right)$. The $\mathrm{FEV}_{1} / \mathrm{FVC}$ ratio was derived from the largest FEV $_{1}$ and FVC. For each subject a predicted lung function variable was calculated with regression equations of the European Respiratory Society. ${ }^{16}$ The residual lung function (largest observed value-predicted value) was used in all analyses.

Among the laboratory workers and the flour workers, peak expiratory flow (PEF) records were made with mini-Wright peak flow meters. At each session, the highest value of three tests was recorded, with the best of two readings within $201 / \mathrm{min}$ of each other. Each subject was asked to make four readings a day, a total of 28 PEF readings over seven days. The PEF variability was calculated for each day with at least two blows, as:

Amplitude \% mean $=100 \star($ maximum - minimum $) /$ mean $(\%)$.

The mean value for all days was used in analyses. Subjects with $<21$ readings over seven days were excluded from analyses.

Bronchial responsiveness was measured by a histamine inhalation test. ${ }^{17}$ If the baseline $\mathrm{FEV}_{1}$ was $<11$ histamine challenge was not performed. The dose provoking a $20 \%$ fall in $\mathrm{FEV}_{1}$ $\left(\mathrm{PD}_{20}\right)$ was estimated by linear interpolation of the last two log dose points, or by extrapolation up to $8 \mu \mathrm{mol}$.

\section{GOLD STANDARD FOR BIS}

In the current study the definition of BIS incorporates information on the histamine challenge test. Also, information was used about bronchial irritability in the past four weeks. The questions that were used were derived from a questionnaire of bronchial irritability symptoms. ${ }^{12}$ Subjects with a $\mathrm{PD}_{20} \leqslant 8 \mu \mathrm{mol}$ histamine, and reporting bronchial irritability in the past four weeks were classified as having BIS.

DEFINITIONS

Table 1 summarises the definitions used in this study. Subjects were classified as having symp-

Table 1 Definitions

\begin{tabular}{|c|c|}
\hline Variable & Criterion \\
\hline NSBHR & $\mathrm{PD}_{20} \leqslant 8 \mu \mathrm{mol}$ histamine \\
\hline BIS & Bronchial irritability in past 4 weeks and NSBHR \\
\hline \multicolumn{2}{|l|}{ Screening instruments: } \\
\hline \multicolumn{2}{|l|}{ Questionnaire } \\
\hline History of asthma & Subjects who had asthma before first employment at current work site \\
\hline History of bronchitis & Subjects who ever had bronchitis or had ever been told that they had bronchitis \\
\hline \multicolumn{2}{|r|}{ 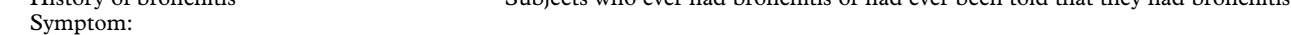 } \\
\hline Chronic bronchitis symptoms & Cough and/or phlegm on most days for 3 months/year \\
\hline Upper respiratory symptoms & $\begin{array}{l}\text { Blocked, itchy, runny, or sneezing nose and/or itchy or runny eyes since first } \\
\text { employment at the site }\end{array}$ \\
\hline Lower respiratory symptoms & $\begin{array}{l}\text { Chest tightness, difficulty breathing and/or wheezing or whistling since first } \\
\text { employment at the site }\end{array}$ \\
\hline Spirometric lung function test & $\begin{array}{l}\mathrm{FEV}_{1} / \mathrm{FVC} \text { residual } \leqslant \text { predicted }-1.644 \star \mathrm{RSD}(\mathrm{RSD}=\text { residual } \mathrm{SD}(6.5 \% \text { for } \\
\text { women, } 7.2 \% \text { for men }))^{16}\end{array}$ \\
\hline Serial peak flow recordings & Amplitude $\%$ mean peak flow $\geqslant 10 \%$ \\
\hline
\end{tabular}


toms if they reported at least one of the following: cough or phlegm on most days for three months a year, upper respiratory symptoms that occurred since the start of work at the site, or lower respiratory symptoms that occurred since the start of work at the site. As recommended by the American Thoracic Society ${ }^{18}$ the chosen cut off for the $\mathrm{FEV}_{1} / \mathrm{FVC}$ ratio was the lower five percentile calculated with the formulas of the European Respiratory Society. ${ }^{16}$ For the peak flow variability the cut off was an amplitude \% mean peak flow $\geqslant 10 \%$, which approximated the upper 95 percentile of the distribution of peak flow variability in these data stratified by occupational group and sex.

ANALYSIS

The relation between the screening instruments and BIS was studied by cross tables, from which sensitivity and specificity were calculated; tests with continuous outcomes were therefore dichotomised into normal and abnormal results (table 1 ). With the sensitivity and specificity of individual tests the likelihood ratios of positive and negative tests were computed. The likelihood ratio and probability before testing were used to calculate the probability of BIS after the tests. ${ }^{19}$ Ideally, the probability before testing summarises all available information at the time of testing. In the current study, the prevalence of BIS within each group was used as an estimate of the probability of disease before testing. After testing the probabilities are calculated for a positive and a negative test outcome. The resulting probability of BIS after one test is used as the probability before the next step. ${ }^{19}$ The diagnostic performance of sequential testing in each group was evaluated by both change in probability of BIS and its sensitivity and specificity.

All analyses were performed with statistical analysis software. ${ }^{20}$

\section{Results}

NUMBER OF SUBJECTS

For 263 acid anhydride workers, 327 laboratory workers, and 237 workers with exposure to flour dusts a complete data set was available comprising subject characteristics, atopic sta- tus, gold standard tests, and information on symptoms and lung function.

In the group of workers exposed to acid anhydrides no peak flow measurements were performed. Among the laboratory workers $65 \%$ performed at least 21 peak flow recordings over seven days, among the flour workers the response was lower, $49 \%$. At the third step of the decision tree for stepwise surveillance, data of 256 laboratory workers and 166 flour workers were analysed.

BIS

The prevalence of BIS was $7 \%$ among acid anhydride workers, $7 \%$ among laboratory workers, and 5\% among flour workers. Among the acid anhydride workers and the laboratory workers another $29 \%$ of the workers and $39 \%$ of the flour workers reported bronchial irritability in the past four weeks but had a normal histamine challenge test. One per cent of the acid anhydride workers, $3 \%$ of the laboratory workers, and $2 \%$ of the flour workers had NSBHR, but did not complain of the bronchial irritability in the past four weeks.

Among the laboratory workers, significantly more subjects without peak flow measurements reported lower respiratory symptoms $(41 \% v$ $27 \%)$, had a positive $\mathrm{PD}_{20}(17 \% v 7 \%)$, and had a borderline significantly higher prevalence of symptoms of bronchitis $(13 \% v 7 \%, p=0.08)$ and of bronchial irritability in the past four weeks $(40 \%$ v 30\%, $\mathrm{p}=0.07)$. Consequently, the prevalence of BIS was significantly higher among laboratory workers without peak flow measurements $(12 \% v 4 \%)$. Among the flour workers, subjects without peak flow measurements had a higher prevalence of bronchial irritability in the past four weeks (47\% v 36\%), although this did not reach significance $(\mathrm{p}=0.09)$.

\section{RELATION BETWEEN SCREENING INSTRUMENTS} AND BIS

Table 2 gives the false positive rate (1specificity) and true positive rate (sensitivity) of the screening instruments for detecting BIS. All three screening instruments, questionnaire, spirometric lung function test, and serial peak flow measurements, were related to the pres-

Table 2 Screening instruments by occupational group and BIS

\begin{tabular}{|c|c|c|c|c|c|c|}
\hline & \multicolumn{2}{|c|}{$\begin{array}{l}\text { Acid anhydride workers }\left(n=263 ; P D_{20}\right. \\
\leqslant 8 \mu m o l=21(8 \%) ; B 14 \text { weeks }=95 \\
(36 \%))\end{array}$} & \multicolumn{2}{|c|}{$\begin{array}{l}\text { Laboratory workers }\left(n=327 ; P_{20}\right. \\
\leqslant 8 \mu m o l=33(10 \%) ; B 14 \text { weeks }=118 \\
(36 \%))\end{array}$} & \multicolumn{2}{|c|}{$\begin{array}{l}\text { Flour workers }\left(n=237 ; P D_{20} \leqslant 8\right. \\
\mu m o l=17(36 \%) ; B 14 \text { weeks }=104 \\
(44 \%))\end{array}$} \\
\hline & $\begin{array}{l}\text { no BIS } \\
246(93.5 \%) \\
n(\%)\end{array}$ & $\begin{array}{l}B I S \\
17(6.5 \%) \\
n(\%)\end{array}$ & $\begin{array}{l}\text { no BIS } \\
304(93.0 \%) \\
n(\%)\end{array}$ & $\begin{array}{l}B I S \\
23(7.0 \%) \\
n(\%)\end{array}$ & $\begin{array}{l}\text { no BIS } \\
226(95.4 \%) \\
n(\%)\end{array}$ & $\begin{array}{l}B I S \\
11(4.6 \%) \\
n(\%)\end{array}$ \\
\hline \multicolumn{7}{|l|}{ Questionnaire: } \\
\hline Chronic bronchitis symptoms & $48(20)$ & $9(53)$ & $23(8)$ & $7(30)^{\star}$ & $41(18)$ & $5(45)^{\star}$ \\
\hline Upper respiratory symptoms & $112(46)$ & $10(59)$ & $137(45)$ & $22(96)^{\star}$ & $103(46)$ & $9(82)^{\star}$ \\
\hline Lower respiratory symptoms & $53(22)$ & $14(82)^{\star}$ & $82(27)$ & $22(96)^{\star}$ & $60(27)$ & $10(91)^{\star}$ \\
\hline$\geqslant 1$ symptom & $131(53)$ & $15(88)$ & $169(55)$ & $23(100)^{\star}$ & $123(54)$ & $11(100)^{\star}$ \\
\hline \multicolumn{7}{|l|}{ Spirometric lung function test: } \\
\hline FVC residual $\leqslant 5$ th percentile & $5(2)$ & $1(6)$ & $6(2)$ & $0(0)$ & $7(3)$ & $0(0)$ \\
\hline $\mathrm{FEV}_{1}$ residual $\leqslant 5$ th percentile & $7(3)$ & $7(41)$ & $6(2)$ & $0(0)$ & $14(6)$ & $2(18)^{\star}$ \\
\hline $\begin{array}{l}\mathrm{FEV}_{1} / \mathrm{FVC} \text { residual } \leqslant 5 \text { th } \\
\text { percentile }\end{array}$ & $15(6)$ & $11(65)^{\star}$ & $10(3)$ & $3(13)^{\star}$ & $18(8)$ & $4(36)^{\star}$ \\
\hline \multicolumn{7}{|l|}{ Serial peak flow recordingst: } \\
\hline Amplitude $\%$ mean $\geqslant 10 \%$ & - & - & $20(10)$ & $4(44)^{\star}$ & $22(19)$ & $2(50)^{\star}$ \\
\hline
\end{tabular}

${ }^{\star} \mathrm{p}<0.05 v$ subjects without BIS (continuous outcome $t$ test, discrete outcomes $\chi^{2}$, or Fisher's exact test.

†For 211 laboratory animal workers including nine subjects with BIS, and 117 flour workers including four subjects with BIS 


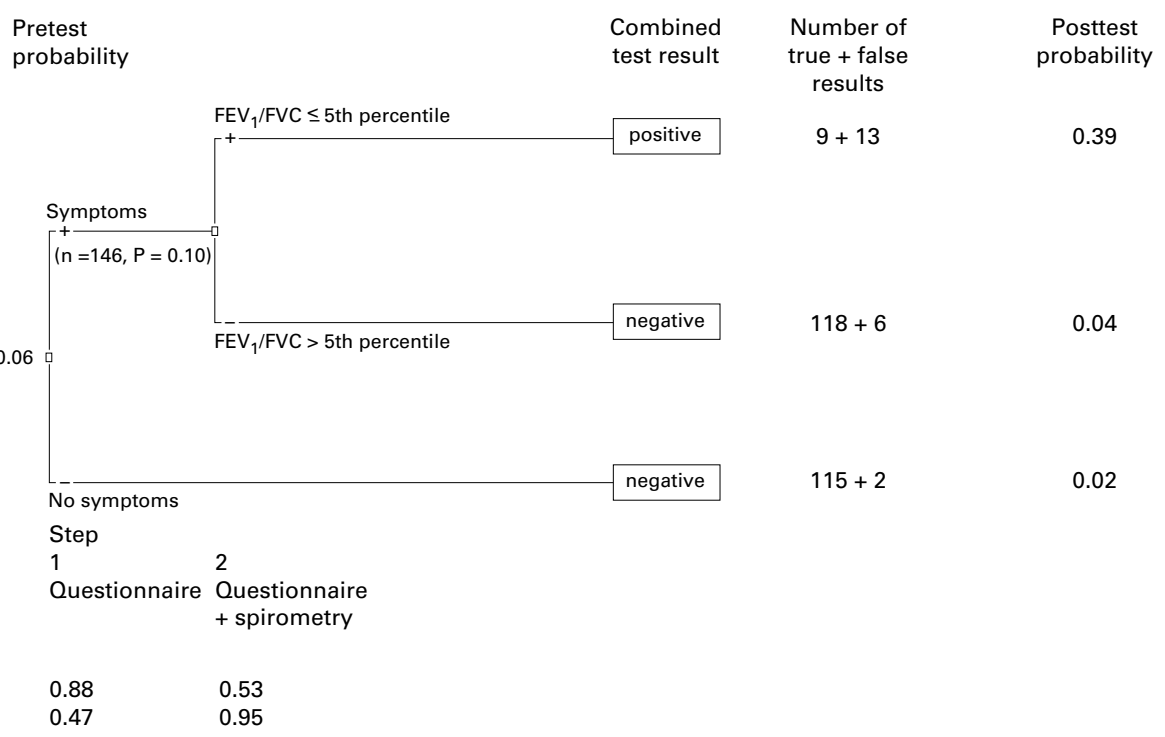

$\begin{array}{lll}\text { Sensitivity } & 0.88 & 0.53 \\ \text { Specificity } & 0.47 & 0.95\end{array}$

Figure 1 Stepwise health surveillance among workers with exposure to acid anhydrides. $P=$ probability of BIS; $n=n u m b e r$ of subjects with test result; positive test outcome=combined testing suggesting BIS; negative test outcome=combined testing suggesting absence of BIS; true results=number of true positive results if combined test outcome is positive and number of true negative results if combined test outcome is negative; false results=number of false positive results if combined test outcome is positive and number of false negative results if combined test outcome is negative.

ence of BIS. If bronchial irritability in the past four weeks was not included in the definition of BIS, but NSBHR alone was used as a gold standard instead, the sensitivity as well as the specificity of symptoms versus NSBHR was smaller, but differences were trivial (sensitivity $78 \%, 90 \%$, and $80 \%$, specificity $36 \%, 38 \%$, and $34 \%$ for acid anhydride workers, laboratory workers, and flour workers respectively).

SEQUENTIAL TESTING

Figures 1-3 show the decision trees for the different occupational groups. Beneath each tree, the sensitivity and specificity of the tree after each consecutive step is given.

The first step (questionnaire on respiratory symptoms) in sequential testing showed that in subjects without symptoms BIS was very unlikely. In the second step, additional spirometry in subjects with respiratory symptoms was very specific, but had low sensitivity. In terms of sensitivity and specificity, an abnormal $\mathrm{FEV}_{1} / \mathrm{FVC}$ ratio was most accurate among the acid anhydride workers. Due to the low sensitivity of lung function testing among the laboratory workers and flour workers with respiratory symptoms, the probability of BIS in subjects with a negative spirometric lung function test dropped only marginally and was still higher than the initial probability before testing. In the third step of sequential testing, among workers with a normal spirometric lung function test, an abnormal peak flow variability augmented the probability of BIS, although the number of false positive results outnumbered the number of true positive results by far. The

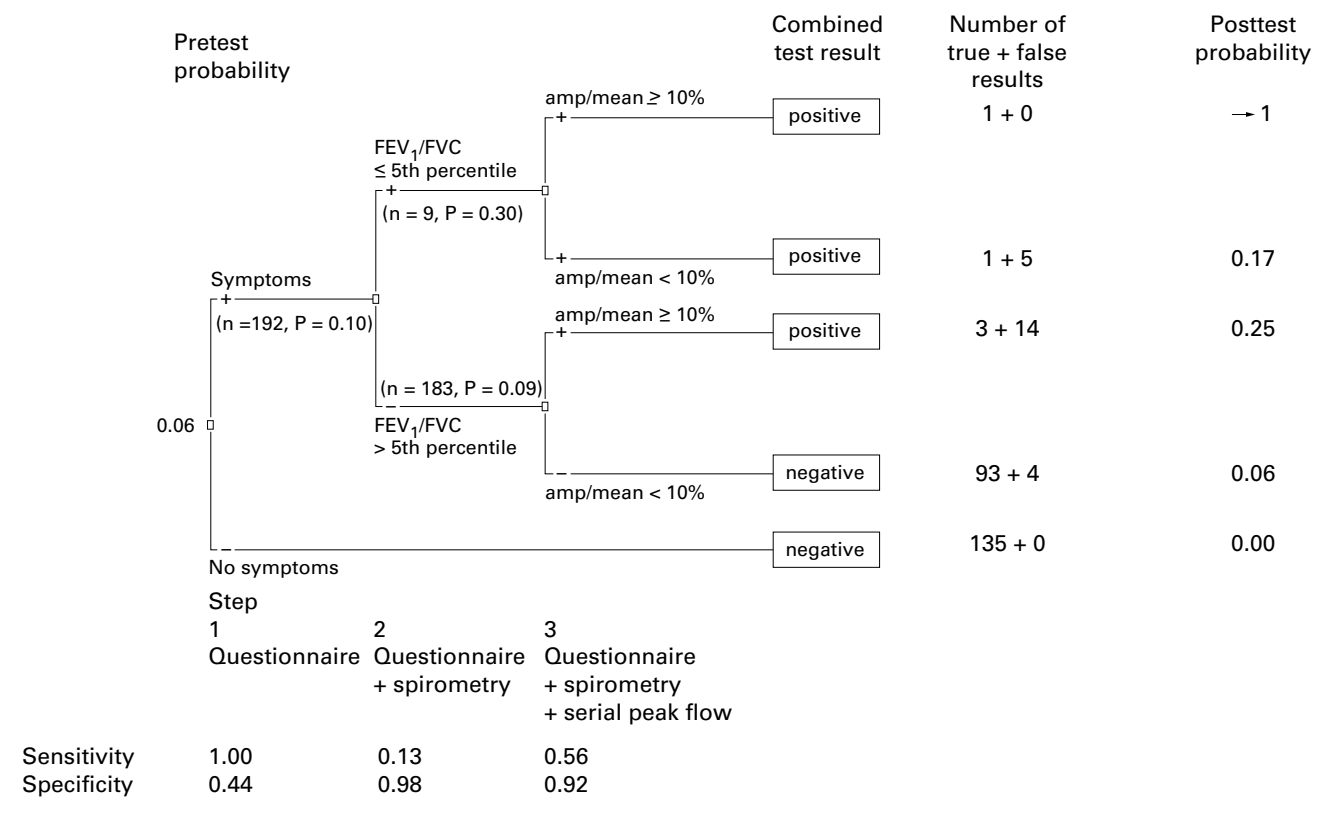

Figure 2 Stepwise health surveillance among workers with exposure to laboratory animals. Explanations as for fig 1 . 


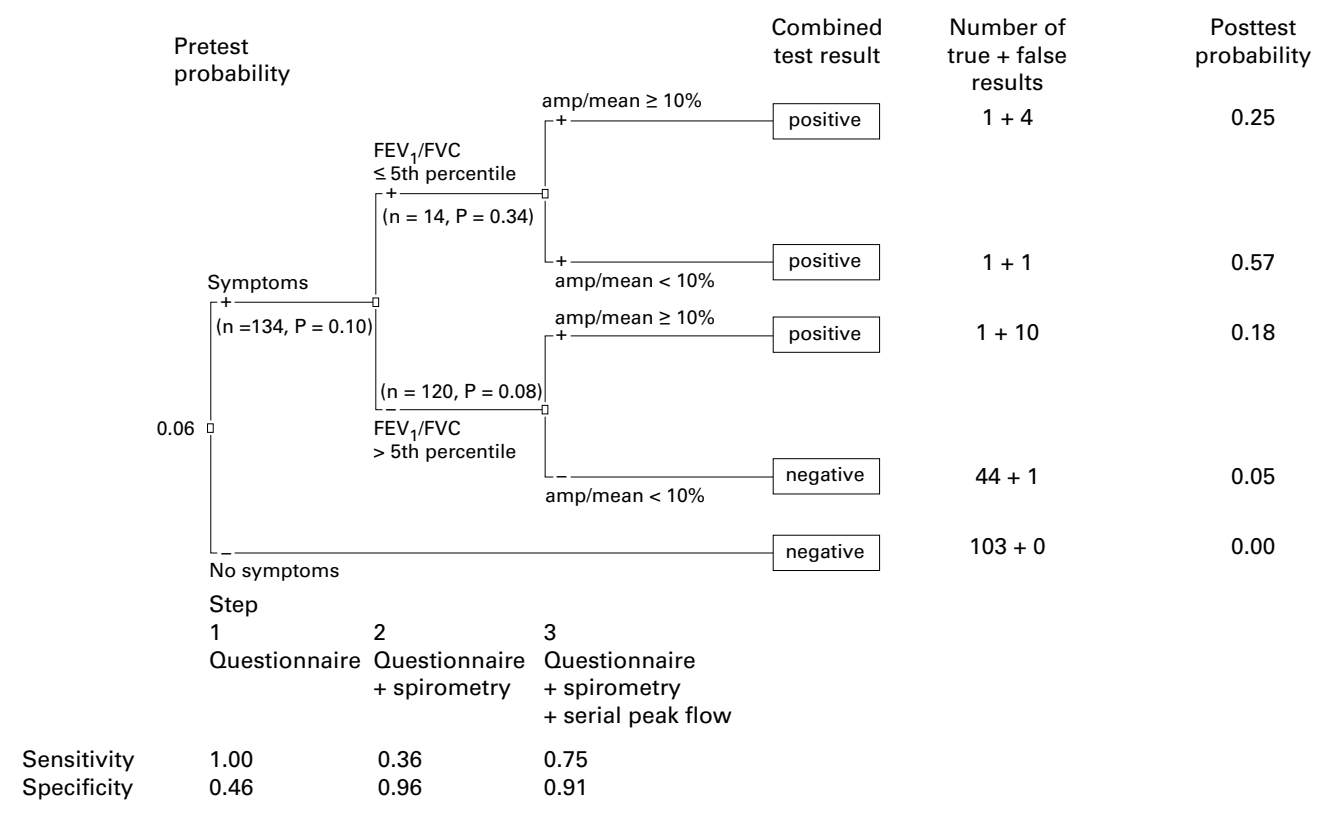

Figure 3 Stepwise health surveillance among workers with exposure to flour dusts. Explanations as for fig 1.

probability of BIS dropped to the initial probability of BIS for subjects with normal peak flow variability. In workers with an abnormal spirometric lung function test, the probability of BIS in laboratory animal workers and flour workers showed contradictory results.

\section{Discussion}

The main goal of health surveillance programmes in occupational health care should be to detect workers with disabling disease early in its course, and ultimately, prevent progression to more severe disease with its associated morbidity and disability. ${ }^{2}$ Ideally, surveillance tests must have good sensitivity to detect all people with the disease under study. To avoid many false positive results, high specificity is also of importance. As screening tests are performed on workers who have no clear symptoms or findings of disease, the probability of disease before testing is very low. Therefore, there will be many undiseased workers who are candidates for false positive results, and few diseased workers. With relatively few truly diseased subjects, the false positive rate strongly affects the interpretation of a positive result; the lower the false positive rate of a test (or the higher the specificity), the higher the probability of disease after testing.

The aim of the current analyses was to evaluate screening instruments currently used in occupational health services on their usefulness to identify subjects with respiratory diseases - such as asthma and chronic bronchitis. The acid anhydride workers are probably more affected by chronic obstructive pulmonary disease induced by smoking. Among laboratory animal handlers asthma will presumably predominate, whereas among the flour worker a mixture of COPD and asthma is not unlikely. Although surveillance might be preferred for work related or even occupational respiratory disease in these occupational groups, we choose to identify NSBHR with the presence of BIS. We think that the first step in surveillance in occupational groups is to detect those subjects with disease, applying general diagnostic tests. Occupational physicians should be aware that identifying BIS in a working population does not mean that it is work related. In a second step, subjects with suspected disease should be tested with specific diagnostic tools to establish the likelihood of a causal relation with agents in the work environment.

In the three study groups, several diagnostic tests had been carried out, which could all be used as either a gold standard test or as part of the screening procedure. Other researchers might have chosen another definition of gold standard or other tests as screening instruments, and we emphasise that the current study is only one possible approach for surveillance of respiratory disorders in occupational health care.

We used a gold standard defined as a positive histamine challenge test in subjects who reported bronchial irritability in the preceding four weeks - for example, wheeze and difficulty in breathing in defined circumstances such as sleep and exercise. Mortagy et al studied bronchial irritability symptoms in combination with NSBHR, and named it the bronchial irritability syndrome (BIS). ${ }^{13}$ They found that only $27 \%$ of subjects with BIS had been diagnosed as asthmatic by their general practitioners. Almost $8 \%$ had been diagnosed as having other respiratory diseases. The current analysis gives no further insight into the relation between BIS and asthma or COPD. However, information on medication for chest or breathing and history of respiratory disease showed that BIS cannot be regarded as a gold standard for asthma alone, but that it can also be an indication of COPD.

We used a stepwise logical approach for surveillance of workers' health, anticipating a better characterisation of BIS with the combina- 
tion of different tests than with the same tests separately, as more information is used. Administration of the tests to be considered had to be feasible within occupational health care; a questionnaire on respiratory symptoms, spirometry, and serial peak flow measurements were chosen as instruments for screening.

Despite differences between the three occupational groups under study in age, smoking, sex, and atopy, the prevalence of BIS was similar and reporting of respiratory symptoms gave a surprisingly similar picture. The definition of symptoms in the current study was very broad, including chronic bronchitis-like symptoms (chronic cough and phlegm), upper respiratory symptoms (eye and nasal symptoms), and lower respiratory symptoms (wheezing, chest tightness, and difficulty breathing). The sensitivity of reporting any of the respiratory symptoms was high, ranging between $88 \%$ and $100 \%$, with a specificity around $46 \%$ in all three occupational groups. This means that almost all subjects with BIS were identified in the first step of the tree, together with many false positive subjects.

In earlier studies the $\mathrm{FVC}, \mathrm{FEV}_{1}$, and $\mathrm{FEV}_{1} /$ FVC ratio have been found to be very specific to detect respiratory obstructive disease $(90 \%-$ $95 \%$ ), but to have a low sensitivity (around $20 \%){ }^{21}{ }^{22}$ More recently, validation of the $\mathrm{FEV}_{1} / \mathrm{FVC}$ for bronchial hyperresponsiveness yielded a sensitivity of $21 \%$, with a specificity of $97 \%$. $^{23}$ In our study, a low FEV1/FVC was more likely to appear in symptomatic subjects with BIS, but except for the acid anhydride workers, its sensitivity was very low. A probable explanation of this difference is the older age distribution of the acid anhydride workers, who are possibly more affected by chronic obstructive pulmonary diseases induced by smoking than the other groups. In patients with COPD there is a strong relation between baseline forced expiratory volume and bronchial hyperresponsiveness to methacholine or histamine. ${ }^{24}$ The flour workers were older than the laboratory workers, and non-allergic mechanisms in these groups have been suggested in earlier cross sectional analysis of these two cohorts, which showed different associations with symptoms and skin reactivity against occupational allergens. ${ }^{15}$ This might explain why $\mathrm{FEV}_{1} / \mathrm{FVC}$ was slightly better in classifying subjects with BIS as abnormal among the flour workers than among laboratory workers. The accuracy of the peak flow measurements can also be related to the studied population. Among the laboratory workers subjects were at risk of developing asthma more than COPD and thus peak flow measurements yield a better performance than spirometry.

As a result of the high specificity of $\mathrm{FEV}_{1} / \mathrm{FVC}$, combining presence of respiratory symptoms and an abnormal $\mathrm{FEV}_{1} / \mathrm{FVC}$ test resulted in a high specificity, and thus a drop in the number of false positive results and a higher probability of BIS if test results were positive. On the other hand, a rise in specificity can only occur at the expense of sensitivity, and therefore the number of false negative results increased. Because the specificity was so much higher than the sensitivity, less precise clinical information is required to confirm the diagnosis of BIS if the $\mathrm{FEV}_{1} / \mathrm{FVC}$ is abnormal than is needed to exclude the diagnosis if the $\mathrm{FEV}_{1} / \mathrm{FVC}$ is normal. Therefore, especially in subjects with respiratory symptoms and normal lung function, further testing is warranted.

We found that the laboratory workers without peak flow measurements had a somewhat higher prevalence of BIS. Despite the short recording period and low compliance that might have caused selection bias, peak flow recording seemed particularly worthwhile among symptomatic workers with a normal $\mathrm{FEV}_{1} / \mathrm{FVC}$. In our analysis, it does not seem necessary to do peak flow tests on those with positive symptoms and abnormal spirometry to further exclude or confirm the diagnosis of BIS. However, the few subjects in this particular step of the tree, should be borne in mind.

Combination of respiratory symptoms, spirometry, and peak flow variability to identify abnormal subjects had a sensitivity of $56 \%$ among laboratory workers and $75 \%$ among flour workers, which compares favourably with the sensitivity of peak flow measurements alone. The corresponding specificity was $\geqslant 90 \%$ in both cases.

Another advantage of combined testing is an economy in the effort to screen for subjects with BIS. The use of a questionnaire is relatively simple and cheap and reduces the number of subjects who would have to perform peak flow measurements. As fewer people perform peak flow measurements, more effort can be put into a higher compliance with serial peak flow measurements. The moderate compliance with peak flow measurements is a disadvantage of this test for epidemiological studies. Furthermore, a combination of respiratory symptoms, spirometry, and serial peak flow resulted in a more detailed estimation of probabilities of BIS after testing.

This study was supported with grants from the Dutch Asthma Foundation and the Biomedical and Health Research Programme of the European Commission. We gratefully acknowledge Professor AJ Newman-Taylor for offering the opportunity to work in his department. Ewout Steyerberg of the Centre of contributed tremendously with his help on decision analysis and contributed
statistics.

1 Ross DJ, McDonald JC. Outcomes in occupational asthma. Presented to winter meeting of the British Thoracic Society. London: BTS, December 1994.

2 Bernstein DI. Surveillance and prevention. In: Bernstein IL, Chan-Yeung M, Malo JL, Bernstein DI, eds. Asthma in the workplace. New York: Marcel Dekker, 1993:359-72.

3 Malo JL, Chan-Yeung M. 1993. Population surveys of occupational asthma. In: Bernstein IL, Chan-Yeung M, Malo JL, et al, eds. Asthma in the workplace. New York: Marcel Dekker, 1993:145-70.

4 Chan-Yeung $M$. Nonspecific bronchial hyperresponsiveness. In: Bernstein IL, Chan-Yeung M, Malo JL, et al, eds. Asthma in the workplace. New York: Marcel Dekker, 1993:189-214.

5 ATS. Standard for the diagnosis and care of patients with chronic pulmonary disease (COPD) and asthma. Am Rev Respir Dis 1987;136:225-44.

6 Venables KM. Prevention of occupational asthma. Eur Respir F 1994;7:768-78.

7 Subramanian D, Guntupalli KK. Diagnosing obstructive lung disease: Why is differentiating COPD from asthma important? Postgrad Med 1994;95:69-85.

8 Britton J, Tattersfield A. Does measurement of bronchial hyperreactivity help in the clinical diagnosis of asthma? Eur f Respir Dis 1986;68:233-8. 
9 Cockroft D, Berscheid B, Murdock B. Unimodal distribution of bronchial responsiveness to inhaled histamine in a

10 Torén K, Brisman J, Järvholm B. Asthma and asthma-like symptoms in adults assessed by questionnaires. A literature review. Chest 1993;104:600-8.

11 Toelle BG, Peat JK, Salome CM, et al. Toward a definition of asthma for epidemiology. Am Rev Respir Dis 1992;146: 633-7.

12 Venables KM, Farrer N, Sharp L, et al. Respiratory symptoms questionnaire for asthma epidemiology: validity and reproducibility. Thorax 1993:48:214-9.

13 Mortagy AK, Howell JBL, Waters WE. Respiratory symptoms and bronchial reactivity: identification of a syndrome and its relation to asthma. BMF 1986;293:525-9.

14 Cullinan P, Lowson D, Nieuwenhuijsen MJ, et al. Work related symptoms, sensitisation, and estimated exposure in workers not previously exposed to laboratory rats. Occup Environ Med 1994;51:589-92.

15 Cullinan P, Lowson D, Nieuwenhuijsen MJ, et al. Work related symptoms, sensitisation, and estimated exposure in workers not previou

16 Quanjer PH, Tammeling GJ, Cotes JE, et al. Lung volumes and forced ventilatory flows. Eur Respir $\mathcal{F}$ 1993;6(suppl 16): $5-40$.
17 Yan K, Salome C, Woolcock AJ. Rapid method for measurement of bronchial responsiveness. Thorax 1983;38. 55-61.

18 ATS. Lung function testing: selection of reference values and interpretative strategies. Am Rev Respir Dis 1991;144: 1202-18.

19 Sox HC, Blatt MA, Higgins MC, et al. Medical decision making. Boston: Butterworth-Heinemann, 1988.

20 SAS Institute. SAS/STAT User's guide, version 6, 4th ed. Vols 1 and 2 . Cary N.C., SAS Institute Inc, 1989.

21 Higgins BG, Keller JB. Seven measures of ventilatory lung function. Population values and a comparison of their ability to discriminate between persons with and without chronic respiratory symptoms and diseases, Tecumseh, Mich. Am Rev Respir Dis 1973;66:253-6.

22 Tashkin DP, Detels R, Coulson AH, et al. The UCLA population study of chronic obstructive disease. II. Determination of reliability and estimation of sensitivity and specificity. Environ Res 1979;20:403-24.

23 Stenton SC, Beach JR, Avery AJ, et al. The value of questionnaire and spirometry in asthma surveillance questionnaire and spirometry in asthma surveillance
programmes in the workplace. Occup Med 1993;43:203-6.

24 Vrugt B, Aalbers R. Inflammation and bronchial hyperresponsiveness in allergic asthma and chronic obstructive pulmonary disease. Respir Med 1993;87(suppl B):3-7.

\section{Occupational and Environmental Medicine and the electronic age}

OEM has an Email address which is 100632.3615@compuserve.com. We welcome contact by Email, including letters to the editor. Many of our reviewers send us their reports by Email, helping to speed up the peer review process.
Our publishing system is now fully electronic, and authors are sending their revised copy to us on disk as well as paper. Watch for revised Instructions to Authors.

The Editor 